\title{
Blend Modified Polymers (Polyethersulfone, Expandable Polystyrene, Polyvenylidinefluride) as a Membrane for Microbial Fuel Cell
}

\author{
Zainab A. Al-Taie ${ }^{1, *}$, Mehdi Salih Shihab ${ }^{1}$ and Shrok Allami ${ }^{2}$ \\ ${ }^{1}$ Department of Chemistry, College of Science, Al-Nahrain University, Baghdad, Iraq \\ ${ }^{2}$ Ministry of Science and Technology, Baghdad, Iraq
}

\begin{tabular}{ll}
\hline \multicolumn{1}{c}{ Article's Information } & \multicolumn{1}{c}{ Abstract } \\
\hline Received: & In this work membrane (proton exchange membrane) by using the blend \\
$27-04-2021$ & polymers (polyethersulfone (PES), Expandable polystyrene (EPS), \\
Accepted: & $\begin{array}{l}\text { polyvenylidinefluride polymer (PVDF)) were prepared. This membrane was } \\
\text { modified by adding organic sulfonic acid to the blend solution pre casting }\end{array}$ \\
Published: & process, and sulfonated by dipping it in diluted sulfuric acid ( ${ }_{2} \mathrm{SO}_{4} 60 \%$ post \\
Pu-06-2021 & casting process. The sulfonation was confirmed via FTIR spectra. The sulfonated \\
Keywords: & membrane was characterized by proton conductivity, ion exchange capacity \\
Microbial fuel cell & (IEC), (-SO ${ }_{3} \mathrm{H}$ ) content, and water uptake. Microbial Fuel Cell (MFC) is \\
Proton exchange membrane & characterized by electrochemical polarization tests and power densities obtained \\
Sulfonation & from it used to evaluate the efficiency of the membrane in the cell. \\
Power density &
\end{tabular}

DOI: 10.22401/ANJS.24.2.02

*Corresponding author: thedarkline275@gmail.com

\section{Introduction}

Fuel cells are electrochemical devices that directly transform the intrinsic chemical energy reaction into electrical energy, in 1839; William Grove first finds the fuel cell [1]. The interest in safer, more environmentally sustainable and more efficient energy sources contributes to increased interest in fuel cells, as there is no output other than water and heat [2]. Microbial Fuel Cell (MFC) is a Biological reactor that through synergistic responses of microorganisms proselytes concoction energy present in natural or inorganic compound substrates to electrical energy [3]. The growth and metabolic activities of microorganisms are used by microbial fuel cells (MFC) to directly transform chemical energy from organic waste into electricity [4]. The MFCs usually contain aerobic anode and cathode compartments separated by the proton exchange membrane (PEM). Protons and electrons generated by organic compound oxidation (via electrochemically active bacteria (EAB)) catabolism in the anode compartment are transferred via the PEM and external circuits to the cathode compartment, respectively. Subsequent $\mathrm{H}_{2} \mathrm{O}$ formation at the cathode occurs through a reaction by the reduction of oxygen with the transferred proton and electron [5].

The present work aims to prepare a membrane for microbial fuel cells and studying the characterization of the polymer blend membrane (proton conductivity, IEC, water uptake, and $\left(-\mathrm{SO}_{3} \mathrm{H}\right)$ content measurements). MFC efficiency was studied via electrochemical polarization and power density curve.

\section{Experimental Procedure}

\subsection{Materials and method}

Materials used for the synthesis of the (PES-EPS-PVDF) blend proton exchange membranes are as specified: polyethersulfone (PES) was purchased from Xiamen keyuan plastic company; expandable polystyrene (EPS) foam beads were purchased from Hangzhou Fuyang Wealth Imp \& Exp Co., Ltd, China; Polyvinylidene fluoride (PVDF) from Allplastics Engineering Pty Ltd; organic sulfonic acid was purchased fromThe General Company for Vegetable Oils Baghdad (Iraq); sulfuric acid $\mathrm{H}_{2} \mathrm{SO}_{4}$ was purchased from CDH-Central Drug House $(P)$ Ltd., New Delhi (India), N, N-Dimethylformamide was purchased from Sinopharm Chemical reagent co., Ltd; Sodium hydroxide pellets $\mathrm{NaOH}$ were purchased from Romil LTD the source convent drive water beatch Cambridge GB-CB25 9QT, United Kingdom; Sodium chloride was purchased from ALPHA CHEMIKA, India.

\subsection{Preparation method of $(\mathrm{P})$ sample}

(PES, EPS, and PVDF) were dried in the microwave oven for (20 $\mathrm{min})$ at a low pulse before dissolving them in DMF [6].

The blend solution was prepared by adding $((0.8 \mathrm{~g})$ of EPS in (2 ml) EPS solution) drop wises to ( $(2 \mathrm{~g})$ of PES in (8 ml) PES solution) with heat and stirring to obtain a homogeneous solution. ( $(0.3 \mathrm{~g})$ of PVDF in $(2 \mathrm{ml})$ PVDF solution) was added by dropping to the previous blend solution with heating and stirring, leaving the solution until getting a homogeneous solution. $(0.5 \mathrm{ml})$ of organic 


\section{Al-Nahrain Journal of Science}

ANJS, Vol.24 (2), June, 2021, pp. 9-13

sulfonic acid was added to the homogenous blend polymers drop wises, Leaving the solution under continuous stirring to obtain homogenous solution. The microwave was used to the blend solution before the casting process at a low pulse for $(5 \mathrm{~min})$. The thin film $(p)$ was prepared by casting the blend solution on the cold glass plate using a casting knife. After that, the membrane was left under cooling conditions then at room temperature. The obtained membrane $(p)$ was washed and soaked in deionized water for $24 \mathrm{~h}$ in order to remove the traces of DMF solvent before dried at $\left(45^{\circ} \mathrm{C}\right)$ for 4 hours. The thickness of the obtained membrane was $(\sim 0.05 \mathrm{~mm})$. The sulfonation reaction was used after the casting process by immersing it in $50 \mathrm{ml}$ of (60\% sulfuric acid) with heat for 3 hours, and then membrane washed using deionized water several times and soaked in deionized water for 24 hours and then dried.

\subsection{Application in MFC \\ MFC Construction}

The laboratory microbial fuel cell was manufactured from two airtight perspex as anode and cathode compartments with holes of $(3 \mathrm{~cm})$ diameter in the center of their interface. Synthesized membranes were inserted in between the anode and cathode compartment using a rubber gasket and tightened by bolts. Anode (graphite sheet) and the cathode (Aluminum sheet) electrodes were positioned into the chamber through the cover of the airtight containers as shown in Figure 1. Before conducting tests, the cathodic chamber must be well aerated. Therefore; choose an air pump to add oxygen to the cathodic chamber that would increase the efficiency of the fuel cell. The electrodes were connected to the data logger and the multimeter to record data into pc. The anode chamber was completely anaerobic.

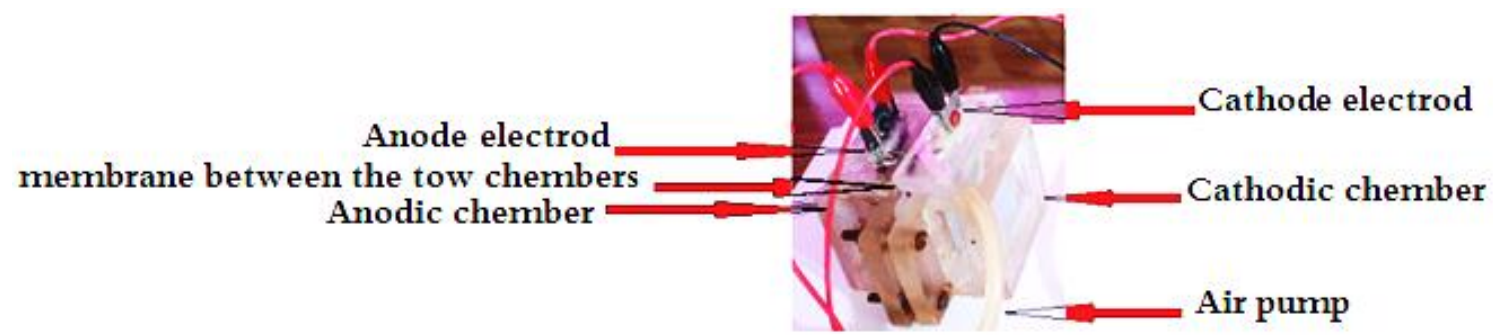

Figure 1. Laboratory Microbial fuel cell.

Anolyte (wastewater) with PH (3-5.5), COD (700-2500 ppm), BOD (400-1200 ppm), and glucose were obtained from the wastewater treatment lab, ministry of science and technology. Catholyte (distilled water with $3.5 \%$ tab salt). MFC usually operates at $\left(37{ }^{\circ} \mathrm{C}\right)$. The electrochemical polarization curve was obtained from using different loads

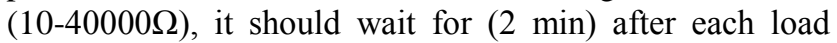
applying, and electrochemical polarization measurements were held after 24 hours of MFC construction. The power density was determined by the equation (1)

$$
P=\frac{(V . I)}{A}
$$

where $V$ and $I$ are the voltage and current, respectively, and $A$ is the electrode zone dipped in the medium [7].

\subsection{Membrane characterization \\ 2.4.1 Proton Conductivity}

The current interrupted method was used to measure the membrane proton conductivity. The membrane soaked in deionized water for 24 hours in order to let it fully hydrated before mounted directly in the home-made conductive test cell. Figure 2 illustrate schematically the membrane electrical contacts in the cell. The outer contacts were for DC current application while the inner ones were for connected the membrane to the digital oscilloscope to monitor the voltage drop after the current interrupted quickly. A constant DC current used its value obtained from the MFC (I-V) characterization curve. The test is done under an inert atmosphere. After the voltage becomes stable, on the digital oscilloscope, the current is interrupted quickly. The in-plane ion conductivity was calculated using the equation (2)'

$$
\sigma=\frac{L}{R \cdot W \cdot T}
$$

where $L$ represents the length between the inner connected wires, $W$ the membrane width and $T$ the membrane thickness, $(R)$ is the membrane resistance calculated from the voltage drop difference [8], $V_{1}$ during current applied and $V_{2}$ after interrupted, to the current applied at the moment of interruption.

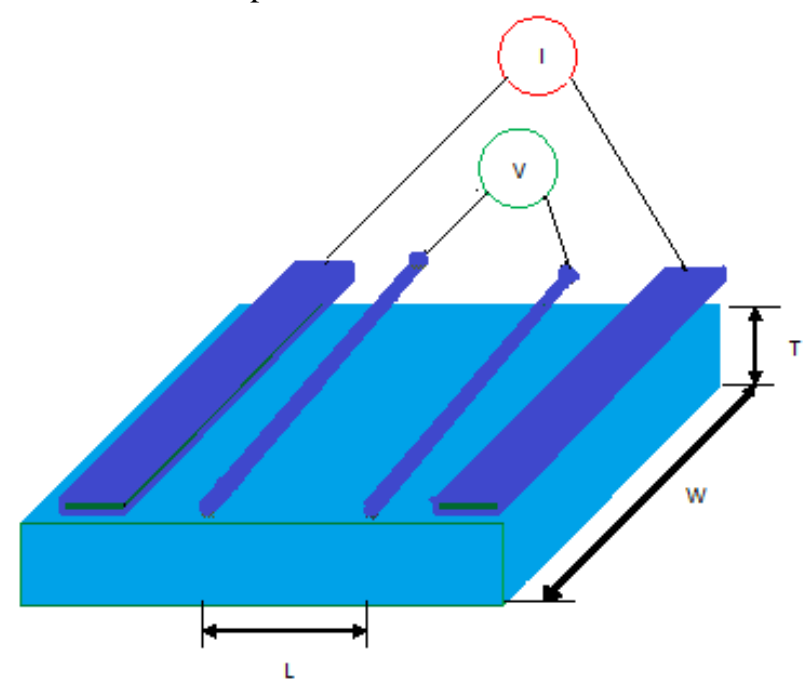

Figure 2. Schematically the membrane electrical contacts in the cell [8]. 


\title{
Al-Nahrain Journal of Science
}

\author{
ANJS, Vol.24 (2), June, 2021, pp. 9-13
}

\subsubsection{Ion Exchange Capacity (IEC)}

Ion exchange capacity (IEC) [meq. $\mathrm{g}^{-1}$ ], is a measure of the ionic content in a dry membrane. The theoretical IEC value can be determined through ${ }^{1} \mathrm{H}-\mathrm{NMR}$ or experimentally calculated [9]. To exchange all protons with ions of sodium, in the sample, the dried samples were weighed and immersed in $(1 \mathrm{M}) \mathrm{NaCl}$ solution for 24 hours. The $\mathrm{HCl}$ content was measured by back titration with $(0.01 \mathrm{M})$ sodium hydroxide. Phenonephthalene solution $(0.1 \%)$ in ethanol/water was used to determine the neutralized point [10]. IEC was calculated using the equation (3).

$$
I E C=\frac{(\text { consumed of } \mathrm{NaOH})(\text { Molarity of } \mathrm{NaOH})}{\text { Dried membrane weight }}
$$

\subsubsection{The analytical acid concentration $\left[-\mathrm{SO}_{3} \mathrm{H}\right](\mathrm{M})$}

$\left[-\mathrm{SO}_{3} \mathrm{H}\right]$ Concentration has a significant effect on proton conductivity and depends on the content of acid and water. In the wet membrane, it can be determined by the equation (4)'

$$
\left[-\mathrm{SO}_{3} \mathrm{H}\right]=\frac{M_{d r y} \times I E C}{V_{w e t}} \times 100
$$

where $M_{d r y}$ is the weight of the dried membrane, $V_{w e t}$ is the volume of the membrane [11].

\subsubsection{Water uptake}

The sulfonated dry membrane has been weighted and submerged for a day in deionized water. The surface area of completely hydrated samples, dried with filter paper and

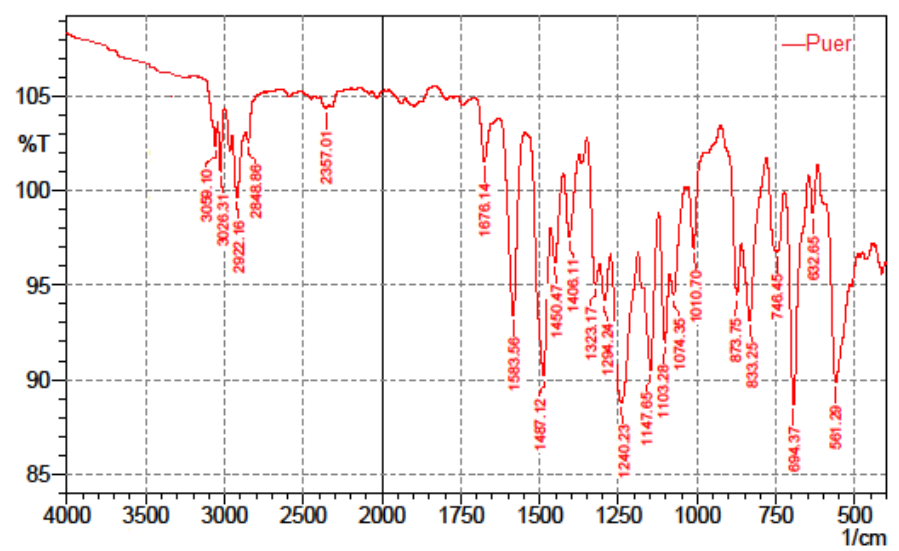

Figure 3. FTIR Spectroscopy for the membranes, pure and (P) sample.

\subsection{Membrane characterizations}

The PVDF volume ratio and the degree of crystallinity play a strong role in the structure and resulting transport properties [14] the utilization of crystalline high molecular weight polymer cause increasing entanglement that increasing the control of water uptake in the blend component [15]. The PVDF homopolymer component helps reduce excessive water swelling and enhancing mechanical property [14] Data measurements for the prepared membrane $P$ proton conductivity $(3.77 \mathrm{~S} / \mathrm{cm})$, weighed water absorption was measured using the equation (5)'

$$
W_{u}(\%)=\frac{W_{w e t}-W_{d r y}}{W_{d r y}} \times 100
$$

where $W_{\text {wet }}$ and $W_{d r y}$ are the weight of fully hydrated and dried samples, respectively [7].

\section{Results and Discussion}

\subsection{FTIR spectroscopy}

FTIR study in the present work was analyzed within the scan range of $4000-500 \mathrm{~cm}^{-1}$. The presence of FTIR spectra was used to confirm the presence of $\left[-\mathrm{SO}_{3} \mathrm{H}\right]$ group on the polymer chains of the $P$ sample. Figure3. Shows the spectra of the pure polymer blend membrane and the sulfonated polymer blend membrane $P$. The peaks at $1585 \mathrm{~cm}^{-1}$ and $1489 \mathrm{~cm}^{-1}$ are attributed to the vibration of the aromatic ring skeleton [11]. The small peak at 3059 $\mathrm{cm}^{-1}$ is attributed to the $\mathrm{C}-\mathrm{H}$ stretching peak of the benzene ring. Stretching band, $2848 \mathrm{~cm}^{-1}$, represents $\mathrm{CH}_{2}$ groups [12]. At $1152 \mathrm{~cm}^{-1}$ the distinctive absorption band for the aromatic sulfone group emerges, and the peak for aryl oxide appears at $1240 \mathrm{~cm}^{-1}$ [13]. The adsorption peak at $1029 \mathrm{~cm}^{-1}$ was characteristic of the aromatic $-\mathrm{SO}_{3} \mathrm{H}$ symmetric stretching vibration $[11,12]$, and the peak at $1176 \mathrm{~cm}^{-1}$ is due to two contributions of $-\mathrm{SO}_{3}$ groups and ring modes of 1:2-substituted benzene [12]. The broad band's showing in $3437 \mathrm{~cm}^{-1}$ indicates the stretching vibrations of $-\mathrm{OH}$ groups [12]. The FTIR spectra revealed the successful sulfonation for the membrane.

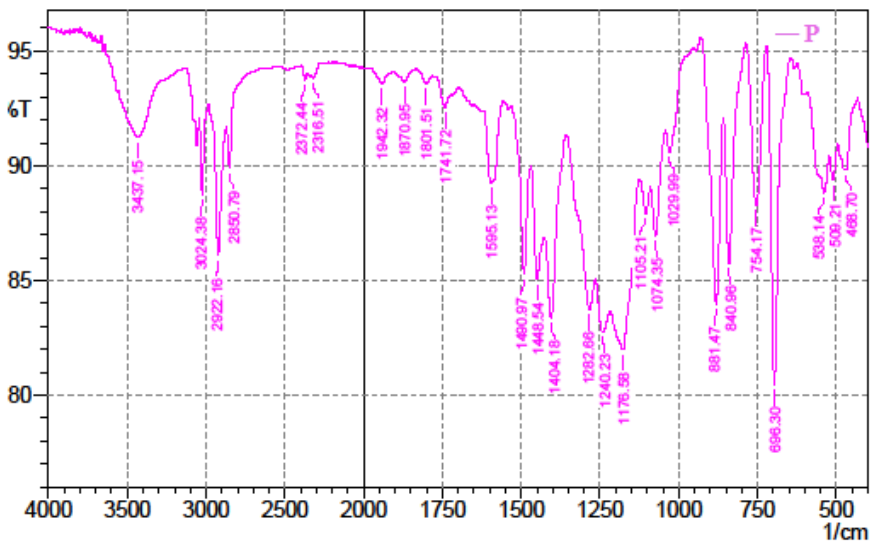

$\left[-\mathrm{SO}_{3} \mathrm{H}\right](0.7366 \mathrm{M})$, water uptake $(160.41 \%)$, power density $\left(4.64 \mathrm{~mW} / \mathrm{cm}^{2}\right)$.

We believed that when we used an equal volume of EPS and PVDF in this sample, high contrast in polarity between hydrophilic and hydrophobic helps the creation of efficient proton tracks as proven by Kazuyama T., [16].

\subsection{MFC Performance with the membranes}

Figure 4 displays the MFC electrochemical polarization curves with the prepared membrane $P$. 


\title{
Al-Nahrain Journal of Science
}

\author{
ANJS, Vol.24 (2), June, 2021, pp. 9-13
}

Tafel slope in the ohmic region represents the cell resistance and depends on the membrane resistance as a factor affecting cell Tafel slope since the other cell components stay the same. For the polarization curve of MFC operated after 24 hours of cell construction, it is clear to note that the cell with $P$ membrane has a low slope, low resistance. The high conductivity of the membrane concluded from the electrochemical test confirms our result from conductivity measurement.

It is clear, dependence the membrane proton conductivity on its composition, degree of sulfonation, and ability to uptake water. When leaving the cell for 24 hours, the membrane absorbs the required water to enhance its cation conductivity that can give a good explanation of the improvement of their conductivity, which affected its efficiency of the cell (Power density after 24 hour is $\left.4.5826\left(\mathrm{~mW} / \mathrm{cm}^{2}\right)\right)$, as shown in Figure 5.

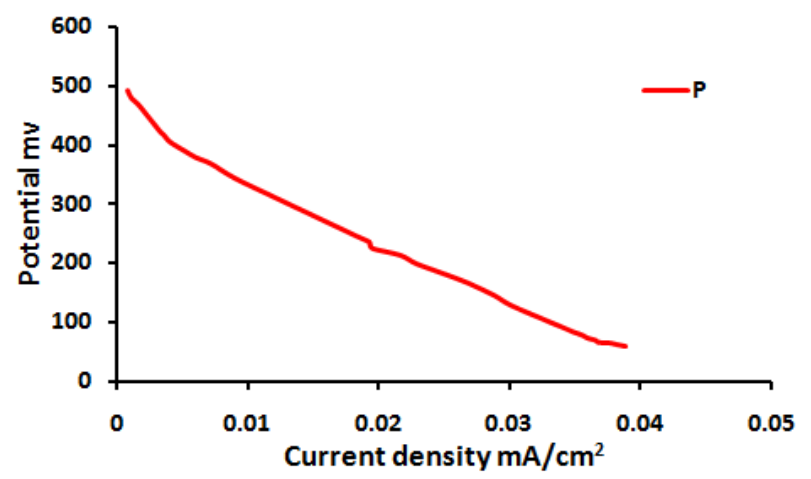

Figure 4. The polarization curve for MFC with the prepared membrane $P$ tested operated after 24 hours cell construction.

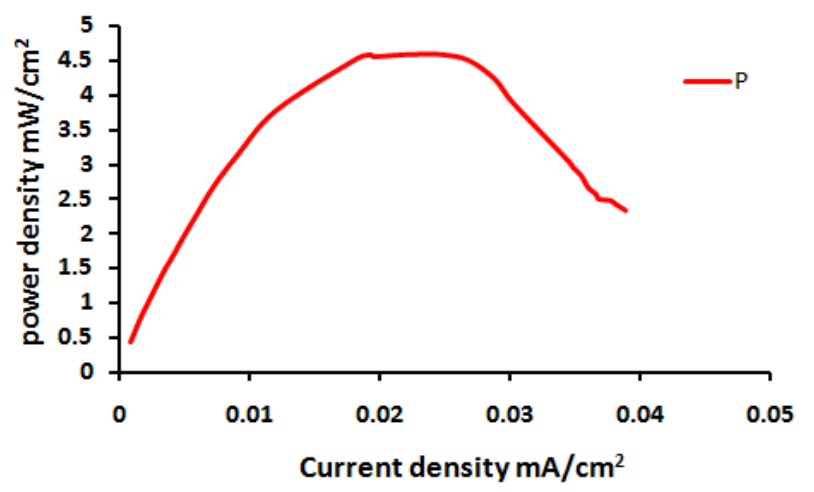

Figure 5. The curve of the power density for MFC with prepared membrane $P$ tested operated after 24 hours cell construction.

\section{Conclusions}

The Blend polymers of (PES, EPS, and PVDF) can be used to prepare proton exchange membrane $P$ by modification it with the sulfonic group using blending Organic sulfonic acid pre-casting process and sulfonation post-casting process. During the membrane preparation, it was found that using microwave heating to complete the homogeneity of the blend reduced the long required heating time. Cooling the substrate before casting the membrane helped in overcoming the difference in the blend's polymers behavior during cooling. The success of the sulfonation is confirmed from FTIR results, while its effect on proton conductivity is measured by the current interrupted method.This membrane is used in the twochamber microbial fuel cell. The membrane has stable open circuit potential, workability, durability, good proton conductivity, and successful works in the microbial fuel cell under constant conditions.

\section{References}

[1] Scott K.; Yu E. H.; Ghangrekar M. M.; Erable B. and Duţeanu N. M.; "United States biological and microbial fuel cells", C. R. En., 4, 277-300, 2012.

[2] Rebecca S. L. Y.; Kaisong Z. and Bradley P. L.; "The effects of sulfonated poly (ether ether ketone) ion exchange preparation conditions on membrane properties", Memb., 3, 182-195, 2013.

[3] Shaikh J. and Niranjan P.; "Microbial fuel cell: design and operation", J. Mic. Bioe, ISSN: 2320-3528, 1-8, 2016.

[4] Siddharth G.; Jean M. F.; Eileen Y. and Jhuma S.; "Influence of temperature and other system parameters on microbial fuel cell performance: Numerical and experimental investigation", Chem. Eng. J., 388, 1-9, 2020.

[5] Taeyoung K.; Sukwon K.; Je H. S.; Youn K. K.; Young H. K. and Jae K. J.; "Characterization of polyester cloth as an alternative separator to nafion membrane in microbial fuel cells for bioelectricity generation using swine wastewater", J. Mic. Bio., 26, 12, 2171-2178, 2016.

[6] Iqbal A.; Farida K.; Ani I.; Rosli B. M. Y.; Zulkafi B. H. and Reddy P.; "Preparation of PES ultrafiltration membrane using novel modified microwave casting solution technique", J. A. Sci, 10(21), 2733-2736, 2010.

[7] Kumar G.; Ram S.; Brajesh K. T. and Richa S.; "Novel proton exchange membranes based on PVC for microbial fuel cells (MFCs)", J. P. Eng., 394, 360-367, 2019.

[8] Work performed by the Florida solar energy center, "Arlington Virginia Procedures for performing in-plane membrane conductivity", Work Performed under DOE Contract, DE-FC36-06GO16028, 1-19, 2008.

[9] Peckham T. J.; Chmeisser J. S.; Rodgers M. and Holdcroft S.; "Main-chain, statistically sulfonated proton exchange membranes: The relationships of acid concentration and proton mobility to water content and their effect upon proton conductivity", J. M. Chem., 17(30), 3255-3268, 2007.

[10] Hyung K. K.; Dong H. K.; Jisu Ch. and Sung Ch. K.; "Compositional effect on the properties of sulfonated and non sulfonated polymer blend membranes for direct methanol fuel cell", Macro. Res., 1, 928-942, 2011. 


\section{$\mathrm{Al}$-Nahrain Journal of Science}

ANJS, Vol.24 (2), June, 2021, pp. 9-13

[11] Nielsen M. M.; "Proton-conducting sulfonated ionomers by chemical modification and atom transfer radical polymerization", Ph.D. Thesis, Kgs. Lyngby: Technical University, Denmark, 2013.

[12] Vona M. L. D.; Sgreccia E.; Tamilvanan M.; Khadhraoui M.; Hassigneux C. and Knauth P.; "High ionic exchange capacity polyphenylsulfone (SPPSU) and polyethersulfone (SPES) cross-linked by annealing treatment: Thermal stability, hydration level and mechanical properties", J. Mem. Sci., 354, 134-141, 2010.

[13] Monaheng L. M.; Arne R. D. V. and Sabelo D. M.; "PES/quaternized-PES blend anion exchange membranes: investigation of polymer compatibility and properties of the blend", J. Mem. Sci. and Res., 4, 93-100, 2018.

[14] Keith S.; Hao Y. E.; Madhao G. M.; Benjamin E. and Mihai D. N.; "Biological and microbial fuel cells, In: comprehensiv renewable energy", Elsevier, United States, ISBN 978-0-08-087872-0, 277-300, 2012.

[15] Narimani R.; "Morphological studies of ionic random graft copolymers based on scattering techniques", Ph.D. Dissertation, Simon Fraser University, 2012.

[16] Kazuyama T.; Tomoya H. and Mitsuru U.; "Locally sulfonated poly (ether sulfone)s with highly sulfonated units as proton exchange membrane", J. P. Sci. Part A, 47, 3444-3453, 2009. 